cultures may have played in producing the illness responses. In previous inoculations, however, passage in man and human tissue culture did not increase the frequency of infections or enhance the virulence for man beyond that seen in the initial inoculum which had been passaged in egg and HK only. This suggests that passage in man did not contribute to virulence. In spite of these considerations the essential point is that an influenza virus of equine origin produced typical human influenzal illness which lends credence to the possibility that in natural conditions equines and equine influenza viruses might contribute to the emergence of new variants of human influenza.

This work was supported in part by the Clinical Research Centers Branch, US National Institutes of Health, and the Vaccine Development Branch, National Institute of Allergy and Infectious Disoases.

R. B. Couch

R. G. Douglas, Jun.

J. A. KASEI

S. RigGS

V. KNIGHT

Baylor College of Medicine,

Departments of Microbiology and Medicine,

Houston, Texas.

Received August 4, 1969.

1 Coleman, M. T., Dowdle, W. R., Pereira, H. G., Schild, G. C., and Chang, W. K., Lancet, ii, 1384 (i968)

${ }^{2}$ Alford, R. H., Kasel, J. A., Lehrich, J. R., and Knight, V., Amer. $J$. Epidemiol., 86, 185 (1967).

${ }^{3}$ Knight, V., in Progress in Medical Virology, 6 (edit. by Barger, E., and Melnick, J. L.), 1 (K arger, Basel and New York, 1964).

- Chanock, R. M., Parrott, R. H., Cook, K., Andrews, B. E., Bell, J. A., Reichelderfer, T., Kapikian, A. Z., Mastrota, F. M., and Huebner, R. J., New Engl. J. Med., 258, 207 (1958).

${ }^{5}$ Stuart-Harris, C. H., Influenza and Other Virus Infections of the Respiratory Tract, 9 (Williams and Wilkins, Baltimore, 1965).

\section{Seasonal Dormancy in Tea (Camellia sinensis L.)}

TEA is cultivated between latitudes $45^{\circ}$ north and $35^{\circ}$ south, and at or near the equator it produces almost the same yield every month. But farther from the equator the winter harvest gradually declines and at latitudes beyond about $16^{\circ}$ there is almost complete winter dormancy which lasts longer with increasing latitudes.

The cause of winter dormancy cannot be ascribed solely to low temperature because tea flushes throughout the year at high elevations near the equator, although tem. peratures there are even lower than winter temperatures in the plains of north-east India ${ }^{1}\left(25^{\circ}-27^{\circ} \mathrm{N}\right)$, where bushes are dormant for about 3 months. Soil water stress and nutrition can also be ruled out as major causes of dormancy because even with an ample supply of water and nutrients throughout the dry winter months tea bushes fail to flush at Tocklai $\left(26^{\circ} 47^{\prime} \mathrm{N}\right)$.

Monthly crop distributions and average day lengths for several tea growing regions from the equator to $30^{\circ}$ north or south indicate that tea bushes pass through a period of complete dormancy when the winter day is shorter than a critical length of about $11 \mathrm{~h} 15 \mathrm{~min}$ for at least 6 weeks. The longer the period of short days, the longer the dormancy.

To test this suggestion experimentally, pruned and unpruned mature tea bushes were exposed to $13 \mathrm{~h}$ days from November 15 to March 21 by providing weak supplementary artificial illumination during the morning and evening. The intensity of illumination from incandescent lamps in the visible part of the spectrum was less than 1 per cent of the visible solar radiation on a bright summer day and was considered too weak to affect net photosynthesis. Half the experimental area was irrigated with $50 \mathrm{~mm}$ of water every month from November to March and the other half was not irrigated. Four similar plots were left as dark controls. Irrigation was discontinued after March, but rainfall in April and May was sufficient to keep the soil fully moist.

Such shoots as were available were harvested from the unpruned plots throughout the winter season and subsequently during April and May. The results showed that irrigation alone increased the winter crop by about 40 per cent and illumination increased it by another 45 per cent. Illumination did not increase the winter crop on unirrigated plots, although it must have induced early bud break as the crop harvested from this plot during April and May clearly shows. With the advent of long days dormancy was also broken in the unilluminated plots, but because of the early start the illuminated plots produced more crop in April-May.

In mid January the pruned and illuminated bushes had twice as many new leaves as the corresponding unilluminated bushes.

In north-east India the tea plant flowers from November to January. Illumination during this period reduced the number of flowers from 376 to $65 / \mathrm{m}^{2}$ of unpruned bush surface.

These results demonstrate that increasing the day to $13 \mathrm{~h}$ during winter, using weak supplementary artificial illumination, enhanced shoot growth, hastened bud break and inhibited flowering.

If winter dormancy of tea induced by short days is tho result of a decrease in the relative concentration of gibberellic acid (GA) in the plant, it should be possible to break dormancy and induce growth in short day conditions by increasing the amount of GA in the dormant plants. This possibility was tested by injecting 10 p.p.m. and 40 p.p.m. respectively of GA into young, single stemmed tea plants on December $30(1027 \mathrm{~h})$, when all tea plants at Tocklai were completely dormant. As well as GA, kinetin was injected into dormant tea plants to investigate whether it directly or in combination with GA affected bud break and subsequent growth. (Kinetin has been reported to inhibit IAA activity ${ }^{2}$.) The compounds were injected into three plants each of two clones by the leaf-stalk injection method ${ }^{3}$.

By the middle of February, the plants supplied with GA completed a flush of growth consisting of two to four leaves when other plants were still dormant. These treated plants started the second flush growth in early March, coinciding with bud break and the first flush growth of the untreated plants and those treated with kinetin. The plants treated with GA completed second flush growth by early May.

Clearly, plants treated with GA grew in the short day conditions of winter while untreated plants remained completely dormant. Thus gibberellic acid replaced long days as it did in the case of Camellia japonica ${ }^{4}$ and Pinus elliottii ${ }^{5}$. Kinetin in the concentrations tried had a significantly antagonistic effect on GA activity.

Winter dormancy of tea therefore seems to be a matter of short day length (or long night length), acting through internal plant growth regulators, and it cannot be broken by the conventional methods of commercial management, but the results reported here open up the possibility of inducing growth in short day conditions either by artificial illumination or by treatment with gibberellic acid.

I thank S. C. Barua for his help and D. H. Laycock for valuable suggestions.

\section{N. BARUA}

Tea Research Association,

Tocklai Experimental Station, Jorhat-8, Assam, India.

Received July 14; revised September 1, 1969.

${ }^{1}$ Hadfleld, W., Nature, 219, 282 (1968).

2 Ropp, R. S. De, Plant Physiol., 31, 253 (1956).

${ }^{3}$ Barua, D. N., Curr. Sci., 25, 249 (1956).

Lockhart, A. J., and Bonner, J., Plant Physiol., 32, 492 (1957).

- Boardeau, P. F., Nature, 182, 118 (1958). 